\title{
Impact of pitch angle fluctuations on airborne lidar forward sensing along the flight direction
}

\author{
Alexander Sergeevich Gurvich ${ }^{1}$ and Victor Alexeevich Kulikov ${ }^{1,2}$ \\ ${ }^{1}$ Obukhov Institute of Atmospheric Physics, Russian Academy of Science, 3 Pyzhevskiy pereulok str., Moscow, \\ 119017, Russia \\ ${ }^{2}$ University of Dayton, 300 College Park, Dayton, OH 45469, USA \\ Correspondence to: Victor Alexeevich Kulikov (victoralexkulikov@gmail.com)
}

Received: 27 April 2017 - Discussion started: 9 June 2017

Revised: 2 September 2017 - Accepted: 5 September 2017 - Published: 19 October 2017

\begin{abstract}
Airborne lidar forward sensing along the flight direction can serve for notification of clear air turbulence (CAT) and help to prevent injuries or fatal air accidents. The validation of this concept was presented in the framework of the DELICAT (DEmonstration of LIdar-based CAT detection) project. However, the strong variations in signal level, which were observed during the DELICAT measurements but not explained, sometimes indicated the need of a better understanding the observational errors due to geometrical factors. In this paper, we discuss possible error sources pertinent to this technique, related to fluctuations of the flight parameters, which may lead to strong signal variations caused by the random deviations of the sensing beam from the forward flight trajectory. We analyze the variations in backscattered lidar signal caused by fluctuations of the most important forward-sensing flight parameter, the pitch angle. The fluctuation values considered in the paper correspond to the error limits of the compensational gyro platform used in civil aviation. The part of the pitch angle fluctuations not compensated for by the beam-steering device in the presence of aerosol concentration variations can lead to noticeable signal variations that can be mistakenly attributed to wind shear, turbulence, or fast evolution of the aerosol layer. We formulate the criteria that allow the recognition of signal variations caused by pitch angle fluctuations. Influence of these fluctuations is shown to be stronger for aerosol variations on smaller vertical scales. An example of DELICAT observations indicating a noticeable pitch angle fluctuation impact is presented.
\end{abstract}

\section{Introduction}

Airborne lidar systems (Fukuchi and Shiina, 2012; Weitkamp, 2006) may play a significant role in warning about, preventing, and compensating for problems caused by atmospheric turbulence. Such systems were previously developed for short-range sounding (Schmitt et al., 2007; Jentink and Bogue, 2005). Medium-range lidars have recently been developed, built, and tested (Huffaker and Hardesty, 1996; Inokuchi et al., 2009a, b; Veerman et al., 2014; Vrancken et al., 2016; Targ et al., 1996; Thales Avionics and ONERA, 2004). One of these systems was developed in the framework of the DELICAT project (DEmonstration of LIdar-based Clear Air Turbulence detection) (Veerman et al., 2014; Vrancken et al., 2016). Medium-range systems are designed to work up to a $20-30 \mathrm{~km}$ sensing distance, which corresponds to $2-10 \mathrm{~min}$ of warning time at the typical flight speed of an airplane or helicopter, respectively. An earlier warning is preferable, and airborne lidar systems with larger sensing distance could be developed in the future.

Sensing of turbulence can be based on backscattered signal from air density fluctuations (Veerman et al., 2014; Feneyrou, 2009; Vrancken et al., 2016) which allows detecting turbulence even in the absence of aerosol scatterers. At the same time, dust, smog, and water vapor also contribute to the backscattered signal. The signal filtration is a good method to exclude undesirable contributions. For example, Hair and co-authors used an extremely narrowband iodine vapor (I2) absorption filter to eliminate the aerosol returns and pass the wings of the molecular spectrum (Hair et al., 2008). At the same time, the depolarization was used in the DELICAT system (Vrancken et al., 2016). Backscattered signal measure- 
ments at different polarizations (Burton et al., 2015; Veerman et al., 2014) will only allow excluding the component produced by nonspherical aerosol particles. The measured signal is, however, composed of the responses of different atmospheric components, which can include the spherical aerosol. The presence of atmospheric aerosol should not be a critical problem for turbulence detection. However, changes in the aerosol layer density during the observation time and the experimental noise, which can affect signal in both polarizations simultaneously, could be a problem for backscattered signal analysis.

There is another technique of CAT detection based on the backscattering enhancement (BSE) effect, which was initially found in theoretical research (Vinogradov et al., 1973) and then experimentally confirmed (Gurvich and Kashkarov, 1977). In the framework of the DELICAT project, the idea of possible turbulence strength estimation based on BSE was theoretically analyzed and reported (Gurvich, 2012; Gurvich and Kulikov, 2013). The two-channel scheme based on backscattering enhancement looks very promising for future airborne applications in light of both thorough theoretical analysis and experimental evidence of success reported in the literature (Banakh and Smalikho, 2011; Banakh et al., 2015; Banakh and Razenkov, 2016a, b). This technique is also sensitive to the airborne-specific noise caused by fluctuations of flight parameters.

The atmospheric effects can bend the sensing beam and prevent lidar turbulence detection based on any principle both methods of turbulence strength estimation discussed in the previous two paragraphs (the method based on air density fluctuations and the method based on BSE effect) are sensitive to these fluctuations. The turbulence anisotropy can noticeably bend the light propagated over such long distances (Gurvich and Chunchuzov, 2003; Sofieva et al., 2010). This impact should be almost negligible for short $15 \mathrm{~km}$ optical paths; the possible laser beam trajectory deviation of about $10 \mathrm{~m}$ is small, taking into account the thickness of the cluster discussed in our paper $(100 \mathrm{~m})$. At the same time, refractive layers can also significantly change the trajectory of optical wave propagation (Werf, 2003; Nunalee et al., 2015). The consideration of such effects can be performed in the framework of geometrical (Southwell, 1982; Werf, 2003; Nunalee et al., 2015) or wave optics (Vorontsov and Kulikov, 2015; Kulikov et al., 2017). Both turbulence anisotropy and possible impact of refractive layers should be considered in the case of extended sensing distances.

A series of atmospheric processes influence the aerosol concentration and turbulence strength on temporal and spatial scales of medium-range sensing. The aerosol concentration can change due to wind shear and evaporationcondensation processes (Ivlev and Dovgalyuk, 1999). For example, small clouds with horizontal characteristic scales of about $1 \mathrm{~km}$ can be displaced completely out of their originally occupied volume in $40-200$ s by wind with a speed within the range of $5-25 \mathrm{~m} \mathrm{~s}^{-1}$ (Liu et al., 2002). Clouds could be split up into numerous small clusters at the horizontal scale of one or several kilometers. Such splitting was observed for different types of aerosol (Chazette et al., 2012; Cadet et al., 2005; Reichardt et al., 2002). The concentrations of both submicron aerosol and gas may change by 2-3 times during the equilibration process at characteristic timescales of about $3 \mathrm{~min}$ (Meng and Seinfeld, 1996). Gravity waves (Nappo, 2013; Fritts and Alexander, 2003) are one of the reasons for CAT (Plougonven and Zhang, 2016; Lane et al., 2003), and new results suggest that turbulence was most strongly forced at the scale of about $700 \mathrm{~m}$ (Koch et al., 2005). The smallest spatial and temporal scales of gravity waves amount to about $1 \mathrm{~km}$ and 1-2 min, respectively ( $\mathrm{Lu}$ and Koch, 2008; Koch et al., 2005; Plougonven and Zhang, 2016). Therefore, lidar forward sensing along the flight direction does not only allow the operational detection of dangerous atmospheric conditions but can also provide information on macrostructures in the aerosol spatiotemporal distribution. At the same time, the signal variations at this timescale may be caused by the variations in lidar-sensing trajectory due to the fluctuations of the flight parameters.

Backscattered signal can also be influenced by changing laser pulse properties or atmospheric propagation effects. Laser instability leads to time variation in both the power and shape of pulses, which results in the change in the backscattered signal. The multipath propagation effect is usually ignored in consideration of backscattered signal, which can significantly degrade the accuracy of the measurement analysis (Godbaz et al., 2012). The detectors can be a source of noise, which depends on the input signal (Acharya et al., 2004). These factors also contribute to the complexity of the signal analysis.

In this paper, we discuss the source of errors, which is specific to the airborne measurements. Variations in aircraft flight height and direction angle are always present in airborne measurements, and they influence the observed backscattered signal. Uncontrolled fluctuations of flight height are usually about several meters and lead to the same height shift along the sensing path. It is highly probable that atmospheric aerosol and turbulence properties do not changes noticeably at the scale of a few meters. Variations in flight direction angle lead to variations in the sensing pulse trajectory. Variations in sensing angles for lidars mounted on the gyro platform should be within the error limits of these compensating systems. The accuracy of pitch angle measurements and compensation for fluctuation is about $0.1-0.2^{\circ} \mathrm{rms}$ (SOMAG AG Jena, 2016; Temp-Avia, 2016). Thus, the angles not compensated for lie in the range of $0.3-0.6^{\circ}$, which corresponds to a $150-300 \mathrm{~m}$ shift at the end of a $30 \mathrm{~km}$ path. Roll and yaw fluctuations do not influence the backscattered signal as long as they cause beam shift, which is small compared to the horizontal scale of clouds, which typical exceeds $1 \mathrm{~km}$. Moreover, pitch angle fluctuation can result in significant signal variations if the trajectory shift caused by the 
angular deviation and the horizontal characteristic scale of aerosol concentration changes are comparable.

There are many experimental observations of variations in aerosol and water vapor concentrations on small vertical (about $100 \mathrm{~m}$ ) and horizontal (several km) scales in the lower atmosphere. Small clouds with such characteristic scales are referred to as "clusters", in order to avoid mixing them up with usual aerosol layers and clouds with the horizontal length of the order of hundreds of kilometers. Clusters can be produced, for example, at the final stage of the collapse of internal gravity waves (Barenblatt and Monin, 1979) or by turbulence (Klyatskin, 2005; Klyatskin and Koshel, 2000).

Observations of the Eyjafjallajökull volcano eruption in 2010 showed small cluster structures as well as huge ash clouds. In the observation carried out by Chazette et al. (2012) by ultraviolet Rayleigh-Mie lidar, clusters with minimal horizontal size corresponding to about $50 \mathrm{~s}$ of aircraft flight time and $80 \mathrm{~m}$ thickness were found (Chazette et al., 2012, Figs. 3 and 4). At the same time, clouds with sizes up to $1 \mathrm{~km}$ in the vertical direction and $100 \mathrm{~km}$ in the horizontal direction were also observed (Chazette et al., 2012). Layers with 1 and $2 \mathrm{~km}$ thickness and concentration changes about 7 times at this scale were found (Dacre et al., 2013, Fig. 3). The same thickness with a concentration jump, which is 2 times smaller, was also found in Turnbull et al. (2012). Simulations predict clouds with a thickness of about $0.5-2 \mathrm{~km}$ (Hervo et al., 2012, Fig. 1), and real observations also show thin layers with a thickness of about $100 \mathrm{~m}$ (Hervo et al., 2012, Figs. 2 and 10). Cirrus cloud splits into numerous clusters with a thickness of about $100 \mathrm{~m}$ at the altitudes between 6 and $11 \mathrm{~km}$ (Reichardt et al., 2002, Fig. 1 or Cadet et al., 2005, Fig. 2b) and stable layers with $1 \mathrm{~km}$ thickness (Cadet et al., 2005, Fig. 2a) were observed. Based on possible wind speed, the horizontal size of these clusters can be estimated as $3-12 \mathrm{~km}$. Their concentration is changing 2-5 times in both vertical and horizontal directions at cluster scales. Ice clouds containing cluster structures with horizontal characteristic scales of about $100 \mathrm{~m}$ were observed, for example, in Haarig et al. (2016, Fig. 2) at altitudes of about 7-11 km. Aerosol clusters in the altitude range of $1-10 \mathrm{~km}$ with the thickness of about $100 \mathrm{~m}$ and the concentration variations of 2-5 times were reported in Burton et al. (2015, Fig. 3; 2014, Fig. 6 dust aerosol; 2015, Figs. 7 and 13; 2014, smoke aerosol in Fig. 9). Clusters with the $100 \mathrm{~m}$ thickness and horizontal size of about a few kilometers were also observed in Hair et al. (2008). Urban plumes measured in Kleinman et al. (2008) also contained clusters with horizontal sizes corresponding to about $1-2$ min of aircraft flight time with 4 times the concentration changes.

Relatively thin and long water vapor layers observed at heights below $11 \mathrm{~km}$ indicate a thickness of about $100 \mathrm{~m}$ or more (Whiteman et al., 1992; Kiemle et al., 2008; Leblanc and McDermid, 2008). An ice layer with $100 \mathrm{~m}$ vertical size can have more than 10 times the concentration changes (Johnson et al., 2012).
Aerosol and water vapor clusters can be routinely observed in the atmosphere in civil aviation flight height range. The shear of a cluster with horizontal characteristic scale of about $1 \mathrm{~km}$ at wind speed of $20 \mathrm{~m} \mathrm{~s}^{-1}$ could happen in about $30-60 \mathrm{~s}$. The evaporation and condensation effects can also influence the time of aerosol cluster evolution. On the other hand, the cluster could disappear from the field of view because of pitch angle fluctuation during the same time. This creates potential ambiguity in the interpretation of the lidar backscattering signal.

In this paper, we discuss the impact of pitch angle fluctuations on both simulated and measured lidar signal in the presence of aerosol clusters with different sizes monitored by an airborne lidar. We formulate the criteria for distinguishing pitch angle fluctuation impact from the evolution of aerosol clusters. The paper is organized as follows: in Sects. 2 and 3, we describe the observation model and its parameters, respectively. The simulation results are presented and discussed in Sect. 4. In Sect. 5, we make our conclusions.

\section{Observation model and typical scales}

Ground-based stationary lidar is the conventional technique for the study of the atmospheric composition, density, and aerosol properties (Zuev and Zuev, 1992). The sensing procedure is as follows: short radiation pulses are produced sequentially by a pulsed laser, and each of them is transformed into a narrow beam by the optical system and sent into the atmosphere. The laser beam scatters on thermodynamic fluctuations of air density (Fabelinskii, 2012), and particles of solid or liquid aerosol (Bohren and Huffman, 2004) scatter the beam. Measured power profiles of the scattered radiation are a function of shot time $t$ and distance $L$ to the scattering volume, with the latter being derived from measured backscatter delay time $\delta t$. For a ground-based lidar with an upwards-directed beam, $L$ equals the altitude of the scattering volume; the intensity fluctuations of lidar response $I$ are proportional to the turbulence strength. This permits solving for turbulence strength distribution along the line of sight (Hauchecorne et al., 2016; Keckhut et al., 2015). As the wind drift occurs, the altitudinal cross section of long-living aerosol clusters can be inferred from $I(L, t)$ relief images in the $(L, t)$ plane as bars, with width depending on both the wind speed and the 3-D cluster structure (Haarig et al., 2016; Hoareau et al., 2012).

The wind drift poses a significant encumbrance to studies of aerosol cluster evolution using ground-based platforms, because it is necessary to distinguish between the temporal evolution of a particular cluster and its drift in space with the wind. While thermodynamic fluctuations of atmospheric air density in time and space may be described under the assumption of their statistical homogeneity and stationarity, this assumption, in practice, often becomes invalid for the description of clusterized aerosol. 

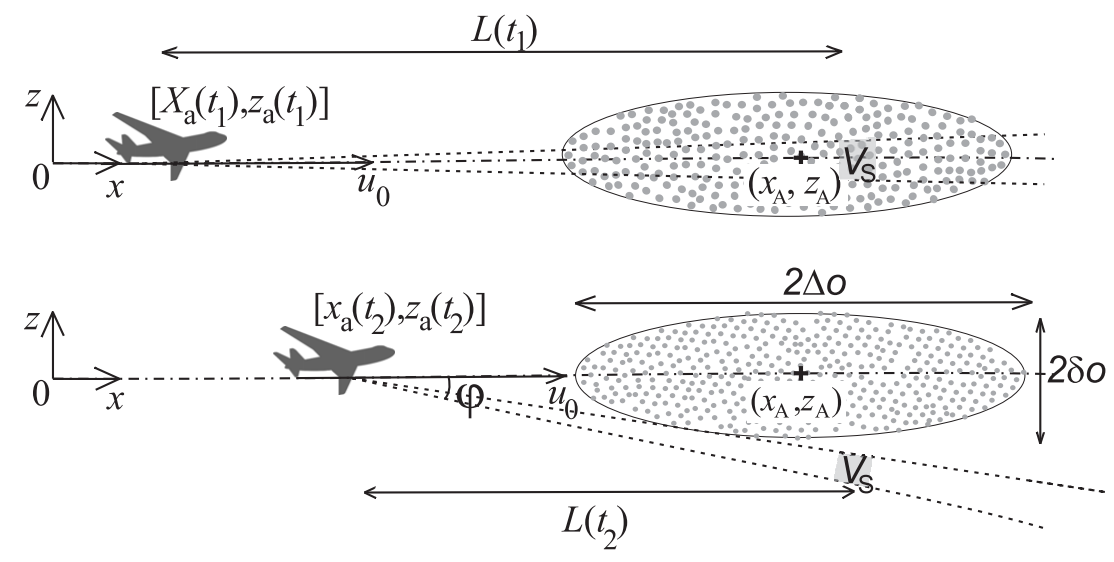

Figure 1. A schematic diagram of lidar measurements of the flight direction from an aircraft. The $x_{\mathrm{a}}(t), z_{\mathrm{a}}(t)$ coordinates represent the observer's coordinates at sequential time points $t_{1}$ and $t_{2}$; the center of the observed clusters is marked with + , and their coordinates are $x_{\mathrm{A}}$, $z_{\mathrm{A}}$.

For the enhancement of civil aviation safety and flight comfort, it was suggested to use an airborne lidar for scanning the atmosphere ahead in the flight direction. The analysis of experimental results demonstrated a rapid spatiotemporal evolution of aerosol clusters (Veerman et al., 2014, Fig. 22). A schematic diagram of lidar measurements that takes into account random pitch angle variations is shown in Fig. 1. In field experiments, noise and distortions of the data are always present. One of the crucial factors is the noise related to uncontrolled fluctuations of the aircraft position and, as a result, of the airborne lidar position. In this work, we develop the results of a previous study (Gurvich and Kulikov, 2016), by considering the spatiotemporal parameters of lidar images of aerosol clusters and by assessing the characteristic scales of clusters, where noise caused by uncontrolled fluctuations of the aircraft position does not impede monitoring their evolution.

The fluctuations of the sensing direction during the flight can be defined by fluctuations of three angles: roll, yaw, and pitch. As the horizontal size of typical aerosol formations is usually large, the azimuthal shifts in the scattering volume due to rolling and yawing are not as significant as its vertical shift, which is characterized by the product of the observation distance $L$ and pitch angle change. For aerosol clusters with the thickness smaller or comparable to the shift in scattering volume, an incidental time modulation of the lidar response from the monitored aerosol cluster may be mistaken for the cluster evolution.

Airborne lidar measurements in the flight direction suggest that it may be possible to observe evolution of the aerosol clusters with evolution time smaller than the observation time. At the same time, variations in the lidar response (Veerman et al., 2014, Fig. 22) could also be caused by variations in the airplane pitch. In this paper, we simulate and discuss the influence of airplane pitch angle variations on the lidar backscattered signal from the aerosol clusters.
It is evident that the backscattered signal coming from the aerosol changes with pitch fluctuations. The scheme in Fig. 1 shows that if the vertical shift in the scattering volume is $L \sin (\varphi)>\delta o$ - where $L$ is the distance between the plane and the scattering volume, $\varphi$ is the angle deflection of the sensing beam from flight direction, and $\delta o$ is the characteristic vertical size of the aerosol cluster - then the signal from the long-living cluster contains distortions caused by scattering volume shift. These distortions may be mistaken for a result of the cluster evolution. In order to avoid the signal variations caused by the pitch angle fluctuations, the condition $L \sin (\varphi) / \delta o<1$ on the maximal acceptable beam angle deviation $\varphi$ should be fulfilled in the presence of aerosol clusters with vertical size about $\delta o$.

If $L \sin (\varphi) / \delta o \geq 1$, then the aerosol cluster may occasionally disappear from the lidar's field of vision. Figure 1 is a schematic representation of the measurements with an airborne lidar that approaches a cluster (depicted by circlets) located on the flight path, with the airspeed $u_{0}$. The cluster thickness $2 \delta o$ is much smaller than its horizontal dimension, $2 \Delta o$. The flight path is shown by the dash-and-dot line. The laser beam is shown by the long dashed line. The scattering volume $V_{\mathrm{S}}$, which moves with the velocity of light $c$ in measurement direction, is colored gray here. The scheme depicts two sequential time moments of measurements. In the second time moment, the beam deflects from the flight direction by angle $\varphi$ and the lidar only registers molecular scattering at the thermodynamic fluctuations of the air density.

There are characteristic times and spatial scales (distances) which are especially important for the analysis of airborne lidar monitoring along the flight direction. Assuming that the molecular scattering is negligibly weak, and neglecting molecular absorption, we may accept the length of molecular extinction $L_{\text {ext }}$ to be the maximum distance. The intensity $I$ of the observed backscatter response decreases with the distance as $L^{-2}$. Together with the sensing pulse magni- 
tude, the internal noises of the receiver, as well as the random nature of aerosol and turbulence, determine the maximum sensing distance $L_{\max }$. Distance $L_{\max }$ is defined as the maximal distance for which we are still able to register backscattered signal. Specifically, in our simulations we limited by signal registered with time delay corresponding to a $16 \mathrm{~km}$ distance assuming, based on DELICAT lidar parameters, that the signal from longer distances could not be registered due to the noise. We assume that $L_{\max }<L_{\text {ext }}$. The minimum timescale is the sensing pulse duration $\tau$, which is about $10 \mathrm{~ns}$ for lasers used in lidars. The lengthwise dimension $l_{\|}$of the scattering volume $V_{\mathrm{S}}$ equals $c \tau / 2$, where $c$ is the light speed. For considered pulse duration, the lengthwise dimension is $l_{\|}=1.5 \mathrm{~m}$. The lateral dimension $l_{\perp}$ is determined by the initial diameter $D_{0}$ of the sensing beam and full divergence angle $\gamma: l_{\perp} \simeq \gamma L+D_{0}$. For the typical values of $\gamma=2 \times 10^{-4} \mathrm{rad}, D_{0}=10 \mathrm{~cm}$, and $L_{\max }=15 \mathrm{~km}$, the estimated value of $l_{\perp}$ is about $3.1 \mathrm{~m}$ at the end of the sensing path. We define the sensing path as the path during which the experimental equipment registers the backscattered lidar signal. Signal record time is determined by the passband of the photodetector and is usually slightly greater than $\tau$. Another characteristic time is the time interval $t_{\max }=2 L_{\max } / c$ of backscatter return. It determines the maximum frequency of sensing pulses. The value of $t_{\max }$ is about $0.1 \mathrm{~ms}$, and the distance $L_{\max }=15 \mathrm{~km}$. Such a time interval is negligible compared to the timescale of detectable variations in atmospheric aerosol systems (Ivlev and Dovgalyuk, 1999). For this reason, the properties of the scattering medium, including the aerosol density and backscattering cross section, are considered to be invariant at time intervals $t_{\max }$ when analyzing the effects of cluster evolution on lidar images.

Lidars, in most practical cases, send recurrent pulses. In Fig. 2 they are seen as a "comb". Based on the absence of coherent relation between pulses, we assume the backscattered signals to be independent for each pulse. In the hierarchy of characteristic times, the value of $t_{\mathrm{obs}}=L_{\max } / u_{0}$ is the time it takes for the aircraft to approach the scatterer after the moment of its observation. The value of $t_{\mathrm{obs}}$ has been used in Gurvich and Kulikov (2016) to define long-living clusters. For observation distances from 10 to $20 \mathrm{~km}$ and modern aircraft velocities, this time may reach hundreds of seconds. The backscattering cross section of aerosol particles may change significantly over the time interval of $t_{\text {obs. }}$. This change is schematically depicted in Fig. 1 by the change in the number and size of scatterers.

\section{Modeling of an aerosol cluster lidar image}

For the lidar image model, we use a Cartesian coordinate system with its $O x$ axis coinciding with the flight direction of the aircraft moving straightforward at a constant altitude. We discuss relatively small distances, $\ll \sqrt{a_{\mathrm{E}} H_{\mathrm{A}}}$, where $a_{\mathrm{E}}$ is the Earth's radius, and $H_{\mathrm{A}}$ is atmospheric scale height.

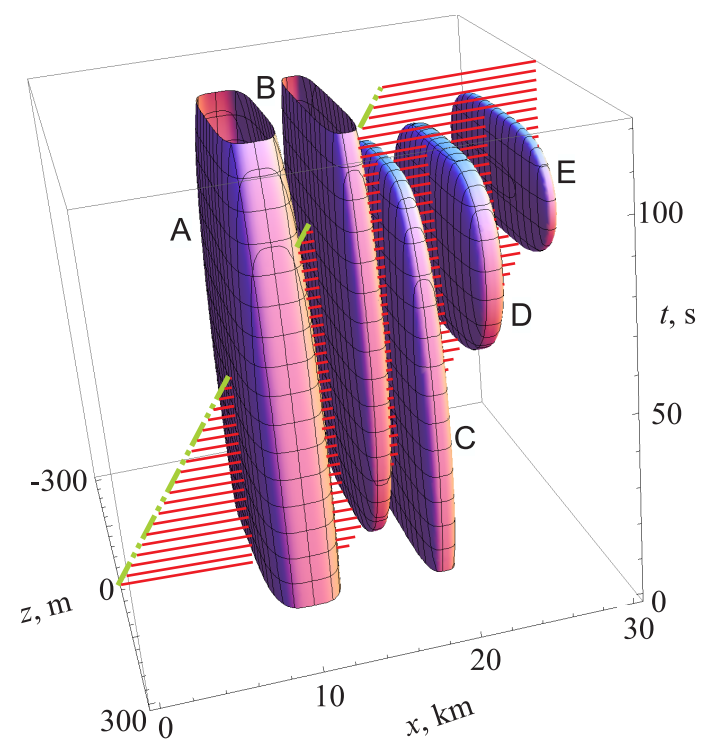

Figure 2. The 3-D images of aerosol clusters $P(x, z, t)$, calculated at $1 / e$ level, for the model given by Eq. (6). The dash-and-dot line is the flight trace; the red "comb" represents sensing laser pulses; $L_{\max }=16 \mathrm{~km} ; \varphi_{0}=0$.

Therefore, the Earth's curvature impact can be neglected. The coordinate system origin is placed somewhere on the flight path; the $O z$ axis is directed along the local vertical. Let us denote the aircraft position at time point $t$ as $x_{\mathrm{a}}(t)=u_{0} \cdot t, z_{\mathrm{a}}(t)$.

To investigate possible artifacts generated by uncontrolled wanderings of the line of sight - which may be caused, for example, by the fluctuations of the aircraft position and errors in the beam-stabilizing system - we should consider the apparent movements of the scattering volume resulting from the above factors. If the distance between the aircraft and the center of the scattering volume at time $t$ is $L$, then the coordinates $x_{\mathrm{S}}, z_{\mathrm{S}}$ of the scattering volume center are

$$
\begin{aligned}
x_{\mathrm{S}}(t) & =x_{\mathrm{a}}(t)+L \cdot \cos (\varphi(t)) \cong x_{\mathrm{a}}(t)+L, z_{\mathrm{S}}(t) \\
& =z_{\mathrm{a}}(t)+L \cdot \sin (\varphi(t)) \cong L \cdot \varphi(t) .
\end{aligned}
$$

Backscattered radiation is detected with the delay

$\delta t=2 L / c$

after time $t_{0}$, when the sensing pulse is sent. Equation (2) allows the derivation of $L$ from measured $\delta t$. Because the light velocity significantly exceeds the aircraft velocity, for the simulation purposes, it is convenient to treat $L(t)$ and $t$, which can both be measured directly, as independent variables.

Below, we perform the analysis of the backscatter signal intensity $I(L, t)$ in the receiving aperture superimposed on the lidar output aperture. We apply the approximation of the single scattering on aerosol particles (Ishimaru, 1978). We use the following notations: $\rho_{\mathrm{A}}(x, y, z, t)$ is the number 
of scatterers per volume unit, or the scatterer density; and $\sigma_{\mathrm{AB}}(x, y, z, t)$ is the aerosol differential backscatter crosssection coefficient. For an arbitrary shaped sensing pulse with its complex envelope $U\left(t, t_{0}\right)$, where $t_{0}$ is a time moment of pulse generation, the intensity registered by the receiver at an arbitrary time point is determined by the expression (Ishimaru, 1978, Eq. 5.35)

$$
\begin{aligned}
I(L, t) & =C s \int_{R_{1}}^{R_{2}} \frac{\rho\left(R^{\prime},\left(t-t_{0}\right)-R^{\prime} / c\right) \sigma_{\mathrm{B}}\left(R^{\prime}, t-R^{\prime} / c\right)}{R_{2}} \\
& \cdot\left|U_{i}\left(t-R^{\prime} / c, t_{0}\right)\right|^{2} e^{-2 \Gamma\left(R^{\prime}, t\right)} \mathrm{d} R^{\prime} .
\end{aligned}
$$

Here $R_{1}=c\left(t-t_{0}\right) / 2$ and $R_{2}=c\left(t-t_{0}+\tau\right) / 2$ are the corresponding positions of the scattering volume boundaries, $t_{0}$ is the time of sensing pulse generation, and $L=\left(R_{1}+R_{2}\right) / 2$ is the position of the scattering volume center along the flight route. The integration is performed along the line of sight, taking into account its direction fluctuations. The factor of $e[-2 \Gamma(R, t)]$ in Eq. (3) describes the extinction and is defined by equation

$$
\Gamma(R, t)=C d \int_{x_{\mathrm{a}}(t)}^{R+x_{\mathrm{a}}(t)} \rho\left(R^{\prime}, t-R^{\prime} / c\right) \sigma_{\mathrm{T}}\left(R^{\prime}, t-R^{\prime} / c\right) \mathrm{d} R^{\prime} .
$$

Here, $\sigma_{\mathrm{T}}$ is the total cross-section coefficient of scattering. The product of $\rho\left(R^{\prime}, t-R^{\prime} / c\right) \sigma_{\mathrm{T}}\left(R^{\prime}, t-R^{\prime} / c\right) \mathrm{d} R^{\prime}$ describes the total losses from molecular and aerosol scatters. Constant factors $C s$ and $C d$ in front of the integrals in Eqs. (3) and (4) account for the sensing pulse energy, beam geometry, receiver aperture, and detector parameters. Equation (3) does not take into account the contribution of weak molecular scattering, which, when the measured intensity $I(L, t)$ is multiplied by $L^{2} e(2 \cdot \Gamma)$, generates a constant background on the lidar image obtained.

Because the lidar pulse is short (10 ns) in comparison to the considered spatial scales, we can use the Dirac function, which significantly simplifies the analytical solution. Under this approximation, in the absence of measurement direction oscillations, signal $I(L, t)$ in receiver aperture is determined by the following equation:

$$
\begin{aligned}
I(L, t) & =I_{\mathrm{M}}(L, t)+I_{\mathrm{A}}(L, t) \\
& I_{\mathrm{M}}(L, t)=\frac{2 C \cdot E_{0}}{c \cdot L^{2}} \rho_{\mathrm{M}}(L, t-L / c) \\
& \cdot \sigma_{\mathrm{MB}}(L, t-L / c) e^{-2 \Gamma(L, t)} \\
& I_{\mathrm{A}}(L, t)=\frac{2 C \cdot E_{0}}{c \cdot L^{2}} \rho_{\mathrm{A}}(L, t-L / c) \\
& \cdot \sigma_{\mathrm{AB}}(L, t-L / c) e^{-2 \Gamma(L, t)}
\end{aligned}
$$

where the observed intensity $I$ has two components $-I_{\mathrm{M}}$, resulting from the molecular scattering, and $I_{\mathrm{A}}$, coming from the aerosol scattering. Here, $E_{0}$ is the pulse total energy; $C$ is the normalizing factor that accounts for the sensing pulse shape, the receiver aperture, and detector features; and $L$ is the distance between the lidar and the scattering volume. Equations (4) and (5) contain terms $\rho_{\mathrm{M}}\left(R^{\prime}, t\right) \sigma_{\mathrm{MB}}\left(R^{\prime}, t\right)$ and $\rho_{\mathrm{A}}\left(R^{\prime}, t\right) \sigma_{\mathrm{AB}}\left(R^{\prime}, t\right)$, which are the products of scatterer density by the cross sections of the molecular and aerosol backscattering, respectively. The term $e(-2 \Gamma(L, t))$ describes extinction, and $\rho\left(R^{\prime}, t-R^{\prime} / c\right) \sigma_{\mathrm{T}}\left(R^{\prime}, t-R^{\prime} / c\right) \mathrm{d} R^{\prime}$ represents the total losses due to molecular and aerosol extinction. This relatively simple model appears to be a good approximation for a sensing laser pulse with the duration of several nanoseconds. For the simulation purposes, we use the following normalized function for the atmospheric aerosol backscattering density:

$$
\begin{aligned}
P(x, z, t) & =\rho_{\mathrm{M}} \sigma_{\mathrm{MB}}(x, y, z, t) / \rho_{\mathrm{M}} \sigma_{\mathrm{MB}}(\max ) \\
& =a \sum_{q} e\left[-\left(\frac{x-x_{0 q}}{\Delta o_{q}}\right)^{4}-\left(\frac{y}{\Delta y_{q}}\right)^{4}\right. \\
& \left.-\left(\frac{z-z_{0 q}}{\delta o_{q}}\right)^{2}-\left(\frac{t-t_{q}}{\Delta t_{q}}\right)^{2}\right] .
\end{aligned}
$$

In this expression, $x$ is the axis collinear to the flight direction; $y$ is the axis perpendicular to both the flight direction and vertical axis; $z$ is the vertical axis, orthogonal to the Earth's surface below the aircraft position; $t$ is the moment of measurement, which we assume to coincide with the moment of pulse generation $t_{0}$, due to the aforementioned smallness of the ratio $L_{\max } /\left(c \cdot \Delta t_{q}\right) \ll 1 ; x_{0 q}, y_{0 q}$ and $z_{0 q}$ are coordinates of the clusters' centers; $t_{q}$ is the time moment of the maximum cluster density; $\Delta t_{q}$ is the typical cluster evolution time; $\Delta o_{q}$ is the cluster scale in the flight direction; and $\delta o_{q}$ is the typical vertical dimension of the cluster. The value of $\Delta y_{q}$ is the transverse size of the cluster. The contribution of fluctuations of the flight direction along $y$ axis to the lidar image noise is negligible because the changes in scatterers' density are smooth. The parameter $\Delta y_{q}$ is chosen to equal $\Delta o_{q}$ for all the simulated clusters. The sequence of five integers $q$, from 1 to 5 , is the sequence order of clusters along the flight path. The model parameters are summarized in the Table 1 . All the five clusters have the same thickness $2 \delta o_{q}=2 \delta o$, which was equal to 100,300 , and $900 \mathrm{~m}$ in different simulations. Figure 2 presents the cluster sequence used in the model for $\delta o=150 \mathrm{~m}$. Aerosol cluster are represented as surfaces calculated at $e^{-1}$ level of values. The distance from the initial position of the aircraft is shown along the $O x$ axis, the flight altitude is shown along the $O z$ axis, and time is shown along the $t$ axis. The aircraft velocity is assumed to be $170 \mathrm{~m} \mathrm{~s}^{-1}$.

The last column of the table contains the unitless ratios $u_{0} \cdot t_{\mathrm{obs}} / \Delta o_{q}$. Because all of them are greater than 1 , we can consider our modeled clusters as long living ones (Gurvich and Kulikov, 2016). We consider "thin" clusters, whose ratios of vertical scales to lengthwise ones are $\delta o / \Delta o \ll 1$. If such clusters are detected in the vertical direction from 
Table 1. Parameters of aerosol clusters.

\begin{tabular}{lccccc}
\hline Cluster & $\begin{array}{c}\Delta o_{q} \\
(\mathrm{~km})\end{array}$ & $\begin{array}{c}\Delta t_{q} \\
(\mathrm{~s})\end{array}$ & $\begin{array}{c}x_{0 q} \\
(\mathrm{~km})\end{array}$ & $\begin{array}{c}t_{q} \\
(\mathrm{~s})\end{array}$ & $u_{0} t_{\mathrm{obs}} / \Delta o_{q}$ \\
\hline $\mathrm{A}$ & 2.0 & 60 & 11.0 & 34 & 5.1 \\
$\mathrm{~B}$ & 1.0 & 40 & 16.3 & 70 & 6.8 \\
$\mathrm{C}$ & 1.0 & 40 & 20.0 & 40 & 6.8 \\
$\mathrm{D}$ & 1.0 & 16 & 24.0 & 80 & 2.7 \\
$\mathrm{E}$ & 0.5 & 10 & 28.0 & 95 & 3.4 \\
\hline
\end{tabular}

a ground-based platform, they are registered as layers in the altitudinal distribution of the aerosol.

Since our work is aimed at the study of the most typical features of the changes in the backscattered lidar signal, we only discuss clusters' shape and relative size, without focusing on the type of particles that produce the signal. Consequently, the value we need to monitor is the normalized backscatter intensity $J_{\mathrm{A}}(L, t)=\left[I_{\mathrm{A}}(L, t)\right] / I_{\mathrm{M}}(L, t)$. As the constant background coming from the scattering on density inhomogeneities does not present any interest in the lidar images, all the figures present the value of $J_{\mathrm{A}}(L, t)$.

Figure 3 shows the lidar image of aerosol clusters, modeled according to model (6). This image is simulated under the assumption of the stable flight altitude and measurement direction. In terms of Eq. (1), this means that $\varphi=0$ and $z_{\mathrm{S}}=$ const, which is equal to the altitude of flight in our simulations. We focus on the problem of the impact of flight parameter fluctuations on measured lidar backscattered signal. The experiment discussed in Veerman et al. (2014, "Introduction") was conducted under clear air conditions. For this reason, for our numerical simulation, we chose the product of scatterer cross section and density $\rho_{\mathrm{M}} \sigma_{\mathrm{MB}}$ to be equal to $2 \times 10^{-2} \mathrm{~dB} \mathrm{~km}^{-1}$ at the cluster's center (concentration $10^{8}$ particles $\mathrm{m}^{-3}$ and density of water $49 \mathrm{mg} \mathrm{m}^{-3}$ ) (Ishimaru, 1978). This value typically corresponds to weak water aerosol clusters in accordance with Fabelinskii (2012) and Ishimaru (1978), which implies that the aerosol scattering does not significantly decrease the propagating laser pulse energy. The values for the other types of aerosol can be found in Vrancken et al. (2016).

The image $J_{\mathrm{A}}$ in Fig. 3 is shown in $\left(L, u_{0} t\right)$ coordinates, in which the cluster with a lifespan of $\Delta t>L_{\max } / u_{0}$ looks like a bar, whose slope with respect to the $O L$ axis equals $\pi / 4$. Longitudinal cluster scale $\Delta o$ determines the image size along the $L$ axis. The image size at an angle of $-\pi / 4$, with respect to the $L$ axis, is determined by $u_{0} \Delta t_{q}$, i.e., the product of aircraft speed by the cluster's lifespan. Measurement of the image length $J_{\mathrm{A}}$ along this direction allows the estimation of the cluster lifespan $\Delta t_{q}$. If the cluster has a long lifespan, such that $u_{0} \Delta t_{q} \gg L_{\max }$, then, for a constant measurement direction, its lidar image is a homogeneous bar.

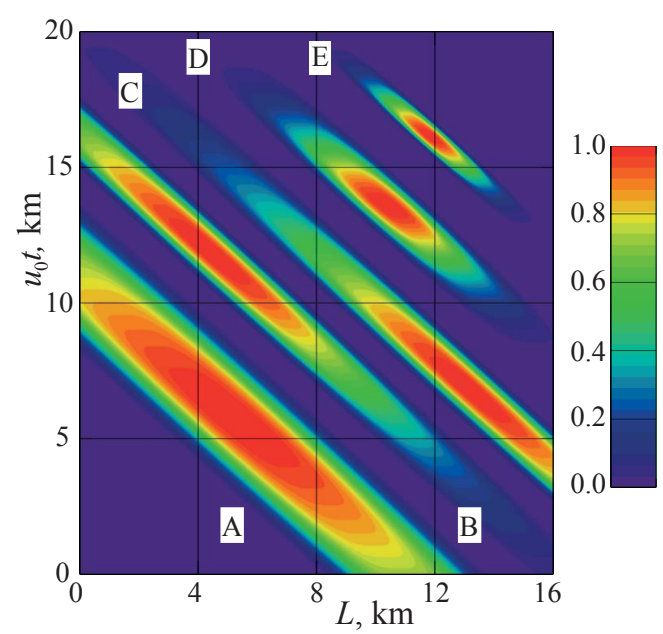

Figure 3. Lidar images $J_{\mathrm{A}}(L, t)$ of aerosol clusters simulated according to the model (Eq. 6) for a constant beam direction aligned with the flight trace. The scale of $J_{\mathrm{A}}$ is given in pseudo-color on the left. The vertical axis corresponds to the product of $u_{0} t_{0}$, where $t_{0}$ is a sensing pulse generation point and $u_{0}$ is the aircraft speed.

\section{The impact of measurement direction fluctuations on cluster lidar images}

Under real-world conditions, the uncontrolled variations in measurement directions always exist due to both vibrations of the carrying platform and fluctuations of flying aircraft altitude. If a cluster is strongly elongated in the horizontal direction, then its lidar image is most sensitive to vertical variations in the measurement direction. For the illustration of the effects caused by sensing beam deviation from the flight direction, we assume that the measurement direction, which is determined in Eq. (1) by the angle $\varphi$, changes periodically with a period of $T_{\varphi}=20 \mathrm{~s}$ according to the equation

$\varphi(t)=\varphi_{0} \cdot\left[1-\cos \left(\phi+2 \pi t / T_{\varphi}\right)\right]$,

where the normalization factor of $\varphi_{0}$ determines the maximum deviation angle from the flight direction; $\phi$ is the correcting parameter. Our choice of the $T_{\varphi}$ is based on one of the characteristic times of pitch angle fluctuations measured in the experiment. These times vary in the range from few to tens of seconds (Fig. 6b and d). The considered effects do not disappear for smaller or larger times; such changes would result only in changing of thickness of the breaches. Given the precision characteristics of modern gyro-stabilizing devices used in civil aviation (Temp-Avia, 2016; SOMAG AG Jena, 2016), we consider here two $\varphi_{0}$ values: $\varphi_{0}=0.3$ and $\varphi_{0}=0.6^{\circ}$. We consider here $z_{\mathrm{a}}(t)=0$.

Figure 4 shows the relation between the deviation of the scattering volume center coordinate $z_{\mathrm{S}}=L \cdot \sin \varphi(t)$, the measurement time $u_{0} t$, and the distance $L$ between the observer and the scattering volume center. The distance $u_{0} t_{0}=$ $20 \mathrm{~km}$ corresponds to $2 \mathrm{~min}$ of airborne observation (for aircraft speed $170 \mathrm{~m} \mathrm{~s}^{-1}$ ). Beam displacement changes from 


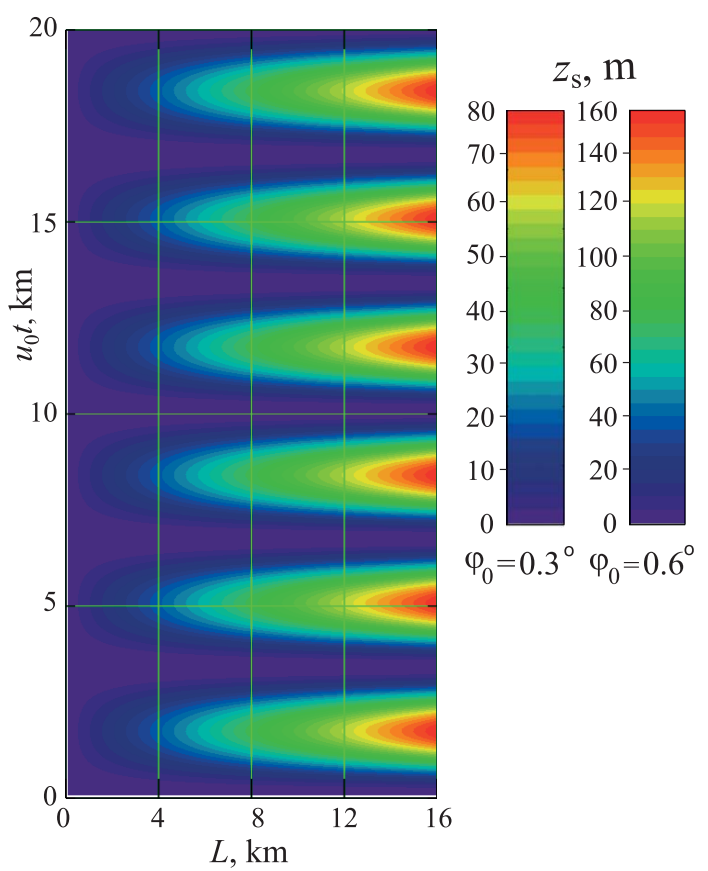

Figure 4. Deviation $z_{\mathrm{S}}$ of the scattering volume center from the flight direction as a function of the pulse generation time $t$ and of the distance $L$.

0 to $160 \mathrm{~m}$ (from 0 to $80 \mathrm{~m}$ ) for $\varphi_{0}=0.3^{\circ}\left(\varphi_{0}=0.6^{\circ}\right)$ for about $10 \mathrm{~s}$. The speed of movement was defined by period $T_{\varphi}=20 \mathrm{~s}$. The correcting parameter $\phi=0$.

Vertical movements of the scattering volume center $z_{\mathrm{S}}$ comparable to or greater than $z_{\mathrm{S}}$ should be visible in the lidar image. This qualitatively follows from the description of the measurement setup in Sect. 2. Lidar images computed in the presence of pitch angle fluctuations in the typical range of the laser gyros $\left(0.1-0.2^{\circ} \mathrm{rms}\right)$ are presented in Fig. 5 .

The same five aerosol clusters described by Eq. (6) and shown in Fig. 2 are taken for lidar image simulations, but their $\delta o$ parameters that determine vertical dimensions are set to different values. Panels (a), (c), and (e) in Fig. 5, grouped in the upper row, show the images simulated at lower oscillation amplitude, $\varphi_{0}=0.3^{\circ}$, for $\delta o$ values of 50 , 150 , and $450 \mathrm{~m}$. The images in the lower row panels $\mathrm{b}, \mathrm{d}$, and $\mathrm{f}$ have a 2 times higher amplitude of $\varphi_{0}=0.6^{\circ}$ and the same $\delta o$ values, respectively. The measurement time is $120 \mathrm{~s}$ for each panel, and the maximum measurement distance $L_{\max }=16 \mathrm{~km}$. Since the maximum vertical deviations of the scattering volume center coordinate $z_{\mathrm{S}}$ from the flight path reach 83 and $168 \mathrm{~m}$, respectively, it is possible to consider cases with $z_{\mathrm{S}}>\delta o$ and $z_{\mathrm{S}}<\delta o$.

The comparison of Figs. 3 and 5 reveals that sensing direction oscillations cause breaches in the clusters' lidar images at large distances $L$ when the deviations of $z_{\mathrm{S}}$ reach the maximum values. These signal fades appear due to the scattering volume shift outside cluster boundaries; the maximal
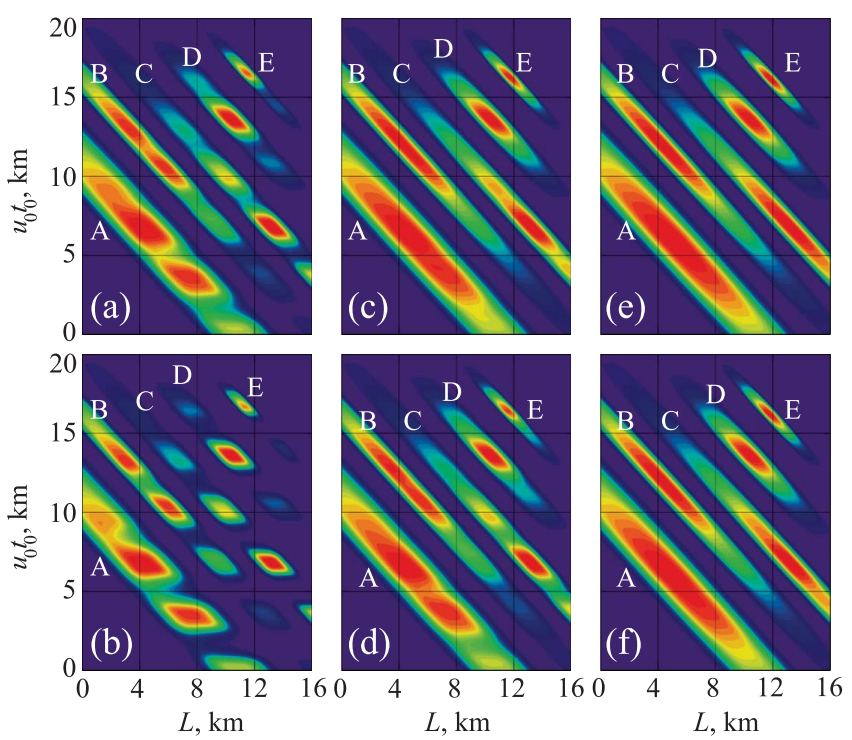

Figure 5. The impact of measurement direction fluctuations on the lidar image $J_{\mathrm{A}}$ of aerosol clusters. The pseudo-colored scale of $J_{\mathrm{A}}$ values is the same as in Fig. 3. Oscillation amplitudes: (a, c, e) $\varphi_{0}=$ $0.3^{\circ}$; (b, d, f) $\varphi_{0}=0.6^{\circ}$. Vertical dimensions: (a, b) $\delta o=50 \mathrm{~m}$; (c, d) $\delta o=150 \mathrm{~m} ;(\mathbf{e}, \mathbf{f}) \delta o=450 \mathrm{~m}$.

shift equals $L \cdot \sin \varphi_{0}$. For this reason the images are more distorted at the right side of each panel of Fig. 5. Image distortions are more intense for thin clusters with low values of $\delta o$.

For example, the backscattered signal at the sensing distance $L=6 \mathrm{~km}$ at the time corresponding to aircraft trajectory coordinate $u_{0} t_{0}=5 \mathrm{~km}$ in the presence of aerosol clusters with thickness $2 \delta o=100 \mathrm{~m}$ (Fig. 5a and b) decreased by about 20 and $60 \%$ from the level without the pitch angle fluctuations (see Fig. 3) for $\varphi_{0}=0.3$ and $\varphi_{0}=0.6^{\circ}$, respectively. The signal decreased by about $10 \%$ in the presence of aerosol clusters with a thickness of $300 \mathrm{~m}$ for $\varphi_{0}=0.6^{\circ}$, and it had no noticeable changes for larger vertical sizes of cluster or smaller angles (Fig. 5c and d). The backscattered signal from the aerosol layer at the sensing distance $L=15 \mathrm{~km}$ at the time corresponded to aircraft trajectory coordinate $u_{0} t_{0}=5 \mathrm{~km}$ with thickness $100 \mathrm{~m}$ decreased by about $85 \%$ for $\varphi_{0}=0.3^{\circ}$ and absent (only background level) for $\varphi_{0}=0.6^{\circ}$. The signal decreases about 35 and $45 \%$ in the presence of aerosol clusters with thickness $300 \mathrm{~m}$ for $\varphi_{0}=0.3$ and $\varphi_{0}=0.6^{\circ}$, respectively, while for the thickness of the cluster about $900 \mathrm{~m}$ the only noticeable change (about $12 \%$ ) can be found for $\varphi_{0}=0.6^{\circ}$. Similar effects can be found in Fig. 5 for each other moment of time (corresponding to flight trajectory coordinate $u_{0} t_{0}$ ).

Figure $5 \mathrm{a}$ and $\mathrm{b}$ show that the breaches appear at the same aircraft position $u_{0} t_{0}$ for all clusters. The lines could be drawn at 2 and $5 \mathrm{~km}-$ as well as at $8,12,15$, and $18 \mathrm{~km}-$ in accordance with the beam direction variations. The value of $L \cdot \sin \varphi_{0}$ is smaller for smaller distance $L$; consequently, 
the breaches' "depth" is smaller for a close distance. Thus, the angle $\varphi_{0}$ could be estimated from the intensity measurements. It may be expected that a natural process intensity, like aerosol evolution due to evaporation or condensation, varies for different clusters. A distortion due to flight direction fluctuations has the same impact on the images of all the clusters observed at the same distance.

The vertical beam deviation caused by pitch angle fluctuations is about 30 and $60 \mathrm{~m}$ at $6 \mathrm{~km}$ distance for maximal amplitude of angle fluctuations $\varphi_{0}=0.3$ and $0.6^{\circ}$, respectively (Fig. 4). It increases up to 75 and $150 \mathrm{~m}$ for the $15 \mathrm{~km}$ distance. The sensing beam can easily move outside the aerosol cluster with a thickness less than the doubled shift size. Even for a movement with a smaller amplitude, the backscattered signal will decrease due to decreasing of the cluster density near its edge.

As shown in Fig. 5, the clusters with the smallest evolution time corresponding to a living time below $30 \mathrm{~s}$ still appeared twice for the strongest fluctuations $\left(0.6^{\circ}\right)$ for the largest sensing distance. This means that we can observe evolution of the smallest considered cluster $(0.5 \mathrm{~km}$ length $)$ with the smallest considered evolution time at the considered sensing distance. The evolution of the cluster is clearly seen in the decreasing signal in the periods between the breaches caused by pitch angle fluctuations. Such decreasing can be seen for all considered clusters with and without pitch angle effects (Fig. 5).

For thickness values large enough, like in panels (e) and (f), the images almost do not differ from the images in Fig. 3 computed with zero $\varphi_{0}$ value, i.e., in the absence of measurement direction oscillations. The data presented in Fig. 5 also suggest the possibility of obtaining actual information about the vertical structure of the aerosol cluster from measurements of $\varphi(t)$ in flight.

\section{Airborne lidar measurements in the presence of pitch angle fluctuations}

The Laboratory of Turbulence and Wave Propagation at the Obukhov Institute of Atmospheric Physics was one of the participants of the DELICAT project. We consider the results of the airborne measurements carried out in the framework of the DELICAT project (Veerman et al., 2014, flight map in Fig. 15). The thorough analysis of CAT detection was performed in Vrancken et al. (2016), Veerman et al. (2014), and Hauchecorne et al. (2016). Here we discuss the examples of strong backscattered signal variations caused by pitch angle fluctuations which were sometimes observed during the experiments. A high-power UV Rayleigh lidar system was installed on an aircraft in a forward-pointing configuration as described in detail in Vrancken et al. (2016). The DELICAT airborne lidar is based on a high-power Nd:YAG laser, which generates $7.7 \mathrm{~ns}$ length pulses at wavelength $1064 \mathrm{~nm}$. The lidar was developed by DLR (German Aerospace Center), while the beam-steering system was developed by Thales
Avionics. The third harmonic $(\lambda=355 \mathrm{~nm})$ with energy about $80 \mathrm{~mJ}$ was used for forward sensing. The angular beam divergence was about $200 \mu \mathrm{rad}$. The lidar receiver contained several subsystems such as a telescope with $140 \mathrm{~mm}$ diameter and optical components for filtering, beam forming, stabilization, and detection. The receiver had two channels: coand cross polarization. Lidar range resolution was about $5 \mathrm{~m}$. Further details of the experimental setup can be found in Veerman et al. (2014) and Vrancken et al. (2016).

The turbulence area detection was based on the lidar measurements of the fluctuation in the density of air associated with the turbulent wind (Feneyrou, 2009; Vrancken et al., 2016; Hauchecorne et al., 2016). This idea was tested at first with the use of the ground-based lidar (Hauchecorne et al., 2016). A detailed discussion of the $C_{n}^{2}$ evaluation method and experimental examples of turbulence lidar signal responses with estimated values of $C_{n}^{2}$ can be found, for example, in Sect. 4b of Hauchecorne et al. (2016) or in Vrancken et al. (2016).

In Fig. 6 only the co-polarized component is shown. For the case that we discuss below, it only differs from the crosspolarized component by the amplitude coefficient. The measured intensity is normalized in order to compensate for the signal decay with the distance $I(L, t)_{\text {norm }}=I(L, t) \times$ $\left(R / R_{2} \mathrm{~km}\right)^{2}$ and presented in Fig. 6 . Though the flight routes for the DELICAT experiments were chosen in order to avoid large amounts of aerosol, the signal variations caused by aerosol backscattering were significant (Fig. $6 \mathrm{~b}$ and d). Civil aviation routes can include more aerosol clouds.

We only present a few minutes of flight N9 measured in France on 8 August 2013. The measurements presented in Fig. 6a were acquired during the time interval from 20:22 to 20:23 UTC time, between the geographical positions (46.26, $6.38)$ and $(46.33,6.48)$ at the altitude of $9.46 \mathrm{~km}$. The measurements presented in Fig. 6d were acquired during the time interval from 20:32 to 20:33 UTC time, between the geographical latitude-longitude positions $(47.20,6.49)$ and $(47.31,6.49)$ at an altitude of $10 \mathrm{~km}$. The aircraft speed was about $170 \mathrm{~m} \mathrm{~s}^{-1}$ in both cases. The backscattered signal contains noise caused by different sources. The lidar signal correction from molecular attenuation is presented in Veerman et al. (2014, Fig. 17). It is mentioned there that the lidar signal is exploitable from 3 to $15 \mathrm{~km}$ due to the saturation effect. In order to avoid this problem completely and ensure that noises due to equipment instability do not impact our research results, we chose $4 \mathrm{~km}$ as the minimal distance for signal analysis.

The experiment shows that the yaw and roll angle fluctuations did not exceed the pitch angle ones (excluding a few moments of significant elevation or descent moments during the flight). The altitude changes during the flight, excluding a few areas of the significant elevation or descent, did not exceed a value of about $10 \mathrm{~m}$. In accordance with the sensing geometry under discussion and possible sizes of the aerosol clusters, only pitch angle fluctuations can result in notice- 

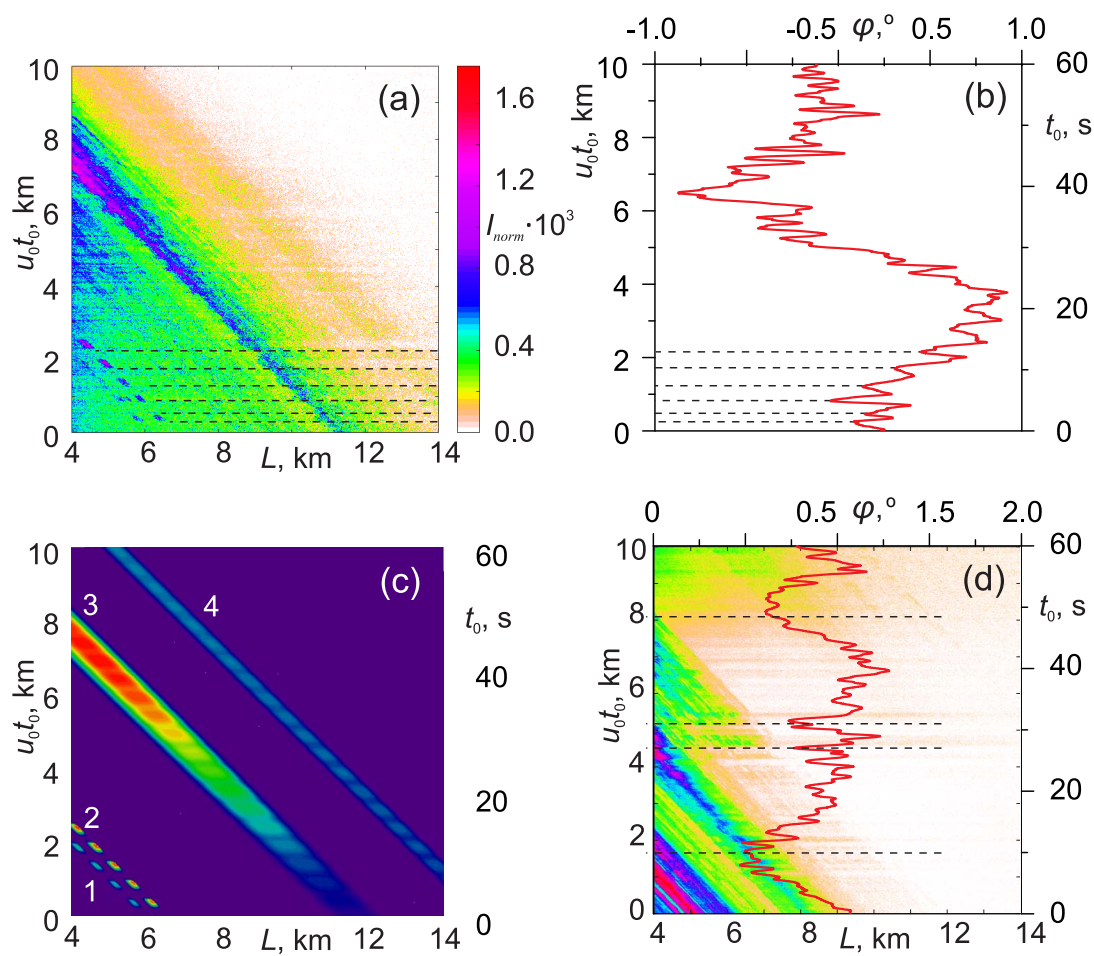

Figure 6. The experimental data and numerical simulations: (a) the normalized intensity $I_{\text {norm }}$ measured during 1 min in airborne experiments (20:22-20:23); (b) measured pitch angle fluctuations correspond to (a); (c) simulations of the experiment presented in (a) - the clusters are marked by their numbers; (d) the normalized intensity $I_{\text {norm }}$ measured during $1 \mathrm{~min}$ in airborne experiments (20:32-20:33).

able signal changes. The pitch angle fluctuations presented in Fig. $6 \mathrm{~b}$ corresponded to the lidar backscattered signal presented in Fig. 6a; both backscattered signal and pitch angle fluctuations for the other observation interval are shown in Fig. 6d. One can see that backscattered signal breaches appeared simultaneously with the pitch angle fluctuations.

The experimental observations shown in Fig. $6 \mathrm{~b}$ and $d$ demonstrate that there are fast and slow pitch angle fluctuations, with the characteristic timescales of 3-4s and about 10-20 s, respectively. The dotted lines in Fig. 6a, b, and d highlight the period of these fluctuations. For visual convenience, only periods of a few fast fluctuations in Fig. 6b and only a few slow fluctuations in Fig. 6d are highlighted. The pitch angle fluctuations result in significant changes in backscattered signal. This impact can be seen, for example, in Fig. 6a, where each signal breach is a result of corresponding pitch angle fluctuations. Two significant signal changes due to slow pitch angle fluctuations can be seen in Fig. $6 \mathrm{~d}$. The two clusters, first at $u_{0} t_{0}=5 \mathrm{~km}(30 \mathrm{~s})$ and second at $u_{0} t_{0}=8 \mathrm{~km}(50 \mathrm{~s})$, suddenly appeared in the field of view due to significant change in the pitch angle presented in the figure by the red curve. In order to resolve the features of backscattered signal caused by the slow pitch angle fluctuations, this type of fluctuations was chosen for the numerical simulation section.
Table 2. Parameters of aerosol clusters: the simulation of the experiment

\begin{tabular}{lrrrrr}
\hline Cluster & $\begin{array}{r}\Delta o_{q} \\
(\mathrm{~m})\end{array}$ & $\begin{array}{r}\Delta t_{q} \\
(\mathrm{~s})\end{array}$ & $\begin{array}{r}x_{0 q} \\
(\mathrm{~km})\end{array}$ & $\begin{array}{r}t_{q} \\
(\mathrm{~s})\end{array}$ & $\begin{array}{r}\delta o_{q} \\
(\mathrm{~m})\end{array}$ \\
\hline 1 & 100 & 120 & 5.7 & 34 & 50 \\
2 & 100 & 120 & 6.2 & 40 & 50 \\
3 & 600 & 26 & 11.1 & 40 & 500 \\
4 & 300 & 120 & 20.0 & 53 & 500 \\
\hline
\end{tabular}

Consider the first and second clusters in Fig. 6a, which firstly detected at distances of 6 and $14 \mathrm{~km}$, respectively. It can be seen that there are breaches in the signal which appeared simultaneously in both responses. The value of observed signal decreased by 3 times from the undisturbed value in the breaches. The breaches demonstrate the same behavior as that simulated (see Fig. 6c), which is typical for the case of the presence of both pitch angle fluctuations and aerosol clusters not compensated for.

In order to simulate the observed effect in Fig. 6a, we chose four clusters with parameters presented in Table 2. The results of simulations are presented in Fig. 6c. The density of the first and last cluster was chosen to be 2 times lower than for the second and third cluster. The first and second clusters have a vertical thickness $2 \delta o$ of about $100 \mathrm{~m}$, while the third 
and fourth one have a thickness of about $1000 \mathrm{~m}$. For this reason, the pitch angle effect on the variations in the backscattered signal from the last clusters is weak. The period of pitch angle fluctuations was chosen as $T_{\varphi}=2.85 \mathrm{~s}$ in accordance with observed fast fluctuations (Fig. 6a). The correcting parameter $\phi=0.5 \pi$. The maximal amplitude $\varphi_{0}$ of the pitch angle fluctuations in the simulation was $0.6^{\circ}$ (corresponds to $0.2^{\circ} \mathrm{rms}$ ). This parameter of the clusters and pitch angle fluctuations allows fitting the experimentally observed decreasing of the signal level and time interval between the signal reappearance (sizes of the breaches). Based on our numerical analysis, we can conclude that the characteristic vertical size of the aerosol clusters provides a noticeable impact on the backscattered signal that is about $50-100 \mathrm{~m}$. The decreasing of vertical size of the aerosol clusters would increase this estimation.

If we assume that $\varphi_{0}=0.15^{\circ}$ (corresponds to $0.05^{\circ} \mathrm{rms}$ ), the experimental results could be approximated with the cluster thickness of $25-30 \mathrm{~m}$.

\section{Conclusions}

In this paper the influence of fluctuations of the flight parameters on images acquired by an airborne lidar system sensing ahead of the aircraft along the flight direction have been discussed with regard to the dependence on characteristic sizes of aerosol layers. It is shown that the pitch angle fluctuations are the important parameter for the airborne lidar sensing ahead in the flight direction in the case when their uncompensated for values result in the sensing beam shift about the vertical size of the aerosol clusters. We performed numerical simulations, which demonstrate the pitch angle fluctuation impact on the lidar signal. The simulations cover the thicknesses of atmospheric aerosol clusters in the range of tens and thousand of meters, accounting for realistic values of pitch angle fluctuations. We also show that lidar forward sensing along the flight direction can potentially provide information about aerosol temporal evolution characteristics even in the presence of pitch angle fluctuations for reasonable cluster size and evolution time at the considered sensing distance.

We demonstrate that pitch angle fluctuations can have a noticeable impact on measurements of the backscattered signal, even for a lidar with a system of compensation for the angle fluctuations. Numerical simulations predict that uncontrolled fluctuations could result in signal noise, including extreme fades and spikes. We show that the aerosol concentration variations on a scale of $100-300 \mathrm{~m}$ have a significant impact on the backscattered signal, if the correction for the angular fluctuation has a residual rms error about $0.1-0.2^{\circ}$, which is typical for beam-steering systems used in civil aviation. Fluctuation influence is shown to depend on the characteristic vertical size of atmospheric aerosol clusters and to introduce larger errors for aerosol density variations on smaller vertical scales. We formulate criteria for distinguishing this impact from the temporal evolution of atmospheric aerosol clouds.

The lidar backscattered signal from the $15 \mathrm{~km}$ sensing distance can disappear (or decrease by about $85 \%$ ) for compensation for pitch angle fluctuations with $0.2^{\circ} \mathrm{rms}\left(0.1^{\circ} \mathrm{rms}\right)$ in the presence of aerosol clusters with a characteristic vertical scale of about $100 \mathrm{~m}$. Aerosol clusters with a thickness of about $300 \mathrm{~m}$ lead to a $45 \%$ (35\%) signal decrease for the same sensing distance and pitch angle fluctuations. The signal level fluctuations of about $60 \%(20 \%)$ can be caused by pitch angle fluctuations with $0.2^{\circ} \mathrm{rms}\left(0.1^{\circ} \mathrm{rms}\right)$ at the $5 \mathrm{~km}$ sensing distance. Pitch angle fluctuations in the presence of aerosol clusters with a thickness of about $100-300 \mathrm{~m}$ and with an angular correction of about $0.1-0.2^{\circ} \mathrm{rms}$ lead to noticeable breaches in the backscattered signal. The presence of two or more aerosol clusters allows for easily distinguishing the areas of significant beam wander due to signal decreasing caused by pitch angle fluctuations.

We presented and discussed an example of airborne lidar experimental observations from the DELICAT project that shows signal variations simultaneously appearing from different aerosol clusters consistent with the signal fades caused by the impact of pitch angle fluctuations in accordance with measurements of the pitch angle fluctuations. Simulations of the experiment are performed assuming an aerosol cluster thickness of about $100 \mathrm{~m}$ (1000 m for the large cluster) for the case of compensation for pitch angle with $0.2^{\circ} \mathrm{rms}$. For compensation with $0.05^{\circ} \mathrm{rms}$ noise, the corresponding value of the aerosol clusters' thickness is $25-30 \mathrm{~m}$ (about $250 \mathrm{~m}$ for the large cluster).

The signal from the areas with significant pitch angle fluctuations can be used only with additional assumptions due to the fact that the sensing beam deviates from the flight trajectory. We need to assume that turbulence strength does not significantly change at the scale of this deviation, which is fulfilled only for the short distances and small angle fluctuations. Otherwise, this deviation would lead to turbulence strength estimation changes which cannot be corrected due to absence of backscattered signal from the actual aircraft trajectory. At the same time, generally speaking, the aerosol clusters' evolution in the absence of significant uncompensated for fluctuations of the pitch angle should not prevent the turbulence strength estimation. The numerical simulations show that, for reasonable parameter ranges, these cases can be distinguished.

Data availability. Research data can be accessed through the Open Science Framework (https://doi.org/10.17605/OSF.IO/7S3P9).

Competing interests. The authors declare that they have no conflict of interest. 
Acknowledgements. The performed analysis was based on the measurements performed by lidar which was developed by DLR (German Aerospace Center), with the beam-steering system developed by Thales Avionics SA. The authors are grateful to the colleagues from the DELICAT project for the experimental data and helpful questions. The authors are grateful to Michael Gorbunov and Olga Fedorova for the thorough manuscript review, Andrey Shmakov for fruitful discussions, and Francis Dalaudier for turning our attention to the significance of measurement direction control. Work on Sects. 1-3 was supported by the Russian Science Foundation (grant RSCF no. 14-27-00134). Work on Sects. 4 and 5 was supported by Russian Foundation for Basic Research (grant no. 16-05-00358-a).

Edited by: Vassilis Amiridis

Reviewed by: Viktor Banakh and one anonymous referee

\section{References}

Acharya, Y. B., Sharma, S., and Chandra, H.: Signal induced noise in PMT detection of lidar signals, Measurement, 35, 269-276, 2004.

Banakh, V. A. and Smalikho, I. N.: Determination of optical turbulence intensity by atmospheric backscattering of laser radiation, Atmospheric and Oceanic Optics, 24, 457-465, 2011.

Banakh, V. A. and Razenkov, I. A.: Lidar measurements of atmospheric backscattering amplification, Opt. Spectrosc.+, 120, 326-334, 2016a.

Banakh, V. A. and Razenkov, I. A.: Refractive turbulence strength estimation based on the laser echo signal amplification effect, Opt. Lett., 41, 4429-4432, 2016 b.

Banakh, V. A., Razenkov, I. A., and Smalikho, I. N.: Laser echo signal amplification in a turbulent atmosphere, Appl. Optics, 54, 7301-7307, 2015.

Barenblatt, G. I. and Monin, A. S.: Similarity laws for turbulent stratified shear flows, Arch. Ration. Mech. An., 70, 307-317, 1979.

Bohren, C. F. and Huffman, D. R.: Absorption and Scattering of Light by Small Particles, WILEY-VCH, Weinheim, Germany, 530 pp., 2004.

Burton, S. P., Vaughan, M. A., Ferrare, R. A., and Hostetler, C. A.: Separating mixtures of aerosol types in airborne High Spectral Resolution Lidar data, Atmos. Meas. Tech., 7, 419-436, https://doi.org/10.5194/amt-7-419-2014, 2014.

Burton, S. P., Hair, J. W., Kahnert, M., Ferrare, R. A., Hostetler, C. A., Cook, A. L., Harper, D. B., Berkoff, T. A., Seaman, S. T., Collins, J. E., Fenn, M. A., and Rogers, R. R.: Observations of the spectral dependence of linear particle depolarization ratio of aerosols using NASA Langley airborne High Spectral Resolution Lidar, Atmos. Chem. Phys., 15, 13453-13473, https://doi.org/10.5194/acp-15-13453-2015, 2015.

Cadet, B., Giraud, V., Haeffelin, M., Keckhut, P., Rechou, A., and Baldy, S.: Improved retrievals of the optical properties of cirrus clouds by a combination of lidar methods, Appl. Optics, 44, 1726-1734, 2005.

Chazette, P., Dabas, A., Sanak, J., Lardier, M., and Royer, P.: French airborne lidar measurements for Eyjafjallajökull ash plume survey, Atmos. Chem. Phys., 12, 7059-7072, https://doi.org/10.5194/acp-12-7059-2012, 2012.

Dacre, H. F., Grant, A. L. M., and Johnson, B. T.: Aircraft observations and model simulations of concentration and particle size distribution in the Eyjafjallajökull volcanic ash cloud, Atmos. Chem. Phys., 13, 1277-1291, https://doi.org/10.5194/acp13-1277-2013, 2013.

Fabelinskii, I. L.: Molecular Scattering of Light, Springer Science and Business Media, Boston, USA, 622 pp., 2012

Feneyrou, P., Lehureau, J.-C., and Barny, H.: Performance evaluation for long-range turbulence-detection using ultraviolet lidar, Appl. Optics, 48, 3750-3759, 2009.

Fritts, D. C. and Alexander, M. J.: Gravity wave dynamics and effects in the middle atmosphere, Rev. Geophys., 41, 1003, https://doi.org/10.1029/2001RG000106, 2003.

Fukuchi, T. and Shiina, T.: Industrial Applications of Laser Remote Sensing, Bentham Science Publishers, Chiba, Japan, 2012.

Godbaz, J. P., Cree, M. J., and Dorrington, A. A.: Closed-form inverses for the mixed pixel/multipath interference problem in amcw lidar, in: Conference on Computational Imaging X, SPIE, 8296, 1-15, 2012.

Gurvich, A. S.: Lidar sounding of turbulence based on the backscatter enhancement effect, Izv. Atmos. Ocean. Phy.+, 48, 585-594, 2012.

Gurvich, A. S. and Chunchuzov, I. P.: Parameters of the fine density structure in the stratosphere obtained from spacecraft observations of stellar scintillations, J. Geophys. Res., 108, 4166, https://doi.org/10.1029/2002JD002281, 2003.

Gurvich, A. S. and Kashkarov, S. S.: On the issue of scattering enhancement in a turbulent medium, Izv. Vuz. Radiofiz.+, 20, 794 800, 1977.

Gurvich, A. S. and Kulikov, V. A.: Lidar sensing of the turbulence based on the backscattering enhancement effect, SPIE LASE, Free-Space Laser Communication and Atmospheric Propagation XXV, 86100 pp., U-86100U, International Society for Optics and Photonics, San Francisco, USA, 2013.

Gurvich, A. S. and Kulikov, V. A.: Airborne Lidar sounding of short-lived aerosol clusters, Atmospheric and Oceanic Optics, 29, 410-414, https://doi.org/10.1134/S1024856016050079, 2016.

Haarig, M., Engelmann, R., Ansmann, A., Veselovskii, I., Whiteman, D. N., and Althausen, D.: $1064 \mathrm{~nm}$ rotational Raman lidar for particle extinction and lidar-ratio profiling: cirrus case study, Atmos. Meas. Tech., 9, 4269-4278, https://doi.org/10.5194/amt9-4269-2016, 2016.

Hair, J. W., Hostetler, C. A., Cook, A. L., Harper, D. B., Ferrare, R. A., Mack, T. L., Welch, W., Izquierdo, L. R., and Hovis, F. E.: Airborne high spectral resolution lidar for profiling aerosol optical properties, Appl. Optics, 47, 6734-6752, 2008.

Hauchecorne, A., Cot, C., Dalaudier, F., Porteneuve, J., Gaudo, T., Wilson, R., Cenac, C., Laqui, C., Keckhut, P., Perrin, J. M., and Dolfi, A.: Tentative detection of clear-air turbulence using a ground-based Rayleigh lidar, Appl. Optics, 55, 3420-3428, https://doi.org/10.1364/AO.55.003420, 2016.

Hervo, M., Quennehen, B., Kristiansen, N. I., Boulon, J., Stohl, A., Fréville, P., Pichon, J.-M., Picard, D., Labazuy, P., Gouhier, M., Roger, J.-C., Colomb, A., Schwarzenboeck, A., and Sellegri, K.: Physical and optical properties of 2010 Eyjafjallajökull volcanic eruption aerosol: ground-based, Lidar and air- 
borne measurements in France, Atmos. Chem. Phys., 12, 17211736, https://doi.org/10.5194/acp-12-1721-2012, 2012.

Hoareau, C., Keckhut, P., Baray, J.-L., Robert, L., Courcoux, Y., Porteneuve, J., Vömel, H., and Morel, B.: A Raman lidar at La Reunion $\left(20.8^{\circ} \mathrm{S}, 55.5^{\circ} \mathrm{E}\right)$ for monitoring water vapour and cirrus distributions in the subtropical upper troposphere: preliminary analyses and description of a future system, Atmos. Meas. Tech., 5, 1333-1348, https://doi.org/10.5194/amt-5-1333-2012, 2012.

Huffaker, R. M. and Hardesty, R. M.: Remote sensing of atmospheric wind velocities using solid-state and $\mathrm{CO}_{2}$ coherent laser systems, P. IEEE, 84, 181-204, https://doi.org/10.1109/5.482228, 1996.

Inokuchi, H., Endo, E., Ando, T., Asaka, K., Tanaka, H., and Hirano, Y.: Development of an Airborne Wind Measurement System, International Symposium on Photoelectronic Detection and Imaging 2009: Laser Sensing and Imaging, edited by: Amzajerdian, F., Gao, C.-Q., and Xie, T.-Y., Proc. SPIE, 7382, 738205, https://doi.org/10.1117/12.836606, 2009a.

Inokuchi, H., Tanaka, H., and Ando, T.: Development of an onboard doppler lidar for flight safety, J. Aircraft, 46, 1411-1415, 2009b.

Ishimaru, A.: Wave Propagation and Scattering in Random Media, Academic Press, New York, USA, 572 pp., 1978.

Ivlev, L. S. and Dovgalyuk, Y. A.: Physics of Atmospheric Aerosol Systems, Saint-Petersburg State University, Saint-Petersburg, Russia, 188 p., 1999.

Jentink, H. W. and Bogue, R. K.: Optical air flow measurements for flight tests and flight testing optical air flow meters, in: Flight Test - Sharing Knowledge and Experience, Meeting Proceedings RTO-MP-SCI-162, Paper 11, Warsaw, Poland, 9-11 May 2005.

Johnson, B., Turnbull, K., Brown, P., Burgess, R., Dorsey, J., Baran, A. J., Webster, H., Haywood, J., Cotton, R., Ulanowski, Z., and Hesse, E.: In situ observations of volcanic ash clouds from the FAAM aircraft during the eruption of Eyjafjallajökull in 2010, J. Geophys. Res., 117, D00U24, https://doi.org/10.1029/2011JD016760, 2012.

Keckhut, P., Courcoux, Y., Baray, J. L., Porteneuve, J., Veremes, H., Hauchecorne, A., Dionisi, D., Posny, F., Cammas, J. P., Payen G, and Gabarrot, F.: Introduction to the Maido Lidar Calibration dedicated to the validation of upper air meteorological parameters, J. Appl. Remote Sens., 9, 094099, https://doi.org/10.1117/1.JRS.9.094099, 2015.

Kiemle, C., Wirth, M., Fix, A., Ehret, G., Schumann, U., Gardiner, T., Schiller, C., Sitnikov, N., and Stiller, G.: First airborne water vapor lidar measurements in the tropical upper troposphere and mid-latitudes lower stratosphere: accuracy evaluation and intercomparisons with other instruments, Atmos. Chem. Phys., 8, 5245-5261, https://doi.org/10.5194/acp-8-5245-2008, 2008.

Kleinman, L. I., Springston, S. R., Daum, P. H., Lee, Y.-N., Nunnermacker, L. J., Senum, G. I., Wang, J., Weinstein-Lloyd, J., Alexander, M. L., Hubbe, J., Ortega, J., Canagaratna, M. R., and Jayne, J.: The time evolution of aerosol composition over the Mexico City plateau, Atmos. Chem. Phys., 8, 1559-1575, https://doi.org/10.5194/acp-8-1559-2008, 2008.

Klyatskin, V. I.: Diffuse and Clusterization of Passive Admixture in Random Hydrodynamic Flows, Moscow Fizmatlit, Moscow, Russia, 149 pp., 2005.

Klyatskin, V. I. and Koshel, K. V.: Simple example of the development of cluster structure of a passive tracer field in random flows, Phys.-Usp.+, 43, 717-723, https://doi.org/10.1070/PU2000v043n07ABEH000743, 2000.

Koch, S. E., Jamison, B. D., Lu, C., Smith, T. L., Tollerud, E. I., Girz, C., Wang, N., Lane, T. P., Shapiro, M. A., Parrish, D. D., and Cooper, O. R.: Turbulence and gravity waves within an upper-level front, J. Atmos. Sci., 62, 3885-3908, 2005.

Kulikov, V. A., Basu, S., and Vorontsov, M. A.: Simulation of laser beam propagation based on mesoscale modeling of optical turbulence and refractivity, in: OSA Conference: Propagation Through and Characterization of Atmospheric and Oceanic Phenomena, PTh3D-3, 26-29 June 2017, San-Francisco, USA, 2017.

Lane, T. P., Sharman, R. D., Clark, T. L., and Hsu, H. M.: An investigation of turbulence generation mechanisms above deep convection, J. Atmos. Sci., 60, 1297-1321, 2003.

Leblanc, T. and McDermid, I. S.: Accuracy of Raman lidar water vapor calibration and its applicability to long-term measurements, Appl. Optics, 47, 5592-5603, 2008.

Liu, Z. S., Wu, D., Liu, J. T., Zhang, K. L., Chen, W. B., Song, X. Q., Hair, J. W., and She, C. Y.: Low-altitude atmospheric wind measurement from the combined Mie and Rayleigh backscattering by Doppler lidar with an iodine filter, Appl. Optics, 41, 7079-7086, 2002.

Lu, C. and Koch, S. E.: Interaction of upper-tropospheric turbulence and gravity waves as obtained from spectral and structure function analyses, J. Atmos. Sci., 65, 2676-2690, 2008.

Meng, Z. and Seinfeld, J. H.: Time scales to achieve atmospheric gas-aerosol equilibrium for volatile species, Atmos. Environ., 30, 2889-2900, 1996.

Nappo, C. J.: An Introduction to Atmospheric Gravity Waves, Academic Press, 365 pp., 2013.

Nunalee, C. G., He, P., Basu, S., Minet, J., and Vorontsov, M. A.: Mapping optical ray trajectories through island wake vortices, Meteorol. Atmos. Phys., 127, 355-368, 2015.

Plougonven, R. and Zhang, F.: Gravity waves generated by jets and fronts and their relevance for clear-air turbulence, in: Aviation Turbulence, Springer International Publishing, Cham, Switzerland, 385-406, 2016.

Reichardt, J., Reichardt, S., Behrendt, A., and McGee, T. J.: Correlations among the optical properties of cirrus cloud particles: implications for spaceborne remote sensing, Geophys. Res. Lett., 29, 13-1-13-4, https://doi.org/10.1029/2002GL014836, 2002.

Schmitt, N. P., Rehm, W., Pistner, T., Zeller, P., Diehl, H., and Nave, P.: The AWIATOR airborne LIDAR turbulence sensor, Aerosp. Sci. Technol., 11, 546-552, 2007.

Sofieva, V. F., Gurvich, A. S., and Dalaudier, F.: Mapping gravity waves and turbulence in the stratosphere using satellite measurements of stellar scintillation, Phys. Scripta, T142, 014043, https://doi.org/10.1088/0031-8949/2010/T142/014043, 2010.

SOMAG AG Jena: product GSM 3000, available at: http://www. somag-ag.de/gsm-3000/ (last access: 11 October 2017), 2016.

Southwell, W. H.: Ray tracing in gradient-index media, J. Opt. Soc. Am., 72, 908-911, 1982.

Targ, R., Steakley, B. C., Hawley, J. G., Ames, L. L., Forney, P., Swanson, D., Stone, R., Otto, R. G., Zarifis, V., Brockman, P., and Calloway, R. S.: Coherent lidar airborne wind sensor II: flight-test results at 2 and $10 \mu \mathrm{m}$, Appl. Optics, 35, 7117-7127, 1996. 
Temp-Avia: product MGV-4V, available at: http://www.temp-avia. ru/index-13.htm (last access: 11 October 2017), 2016 (in Russian).

Thales Avionics and ONERA: A $1.5 \mu \mathrm{m}$ LIDAR demonstrator of low airspeed measurement for civil helicopter, in: Proceedings of the 30th European Rotorcraft Forum, 14-16 September 2004, Marseilles, France, 2004.

Turnbull, K., Johnson, B., Marenco, F., Haywood, J., Minikin, A., Weinzierl, B., Schlager, H., Schumann, U., Leadbetter, S., and Woolley, A.: A case study of observations of volcanic ash from the Eyjafjallajökull eruption: 1. In situ airborne observations, J. Geophys. Res., 117, D00U12, https://doi.org/10.1029/2011JD016688, 2012.

Veerman, H. P. J., Vrancken, P., and Lombard, L.: Flight Testing Delicat - A Promise for Medium-Range Clear Air Turbulence Protection, European 46th SETP and 25th SFTE Symposium 2014, 15-18 June 2014, Lulea, Sweden, 2014.

Vinogradov, A. G., Kravtsov, Y. A., and Tatarskii, V. I.: Backscattering enhancement effect on bodies placed in a medium with random inhomogeneities, Izv. Vuz. Radiofiz.+, 16, 1064-1070, 1973.
Vorontsov, M. A. and Kulikov, V. A.: Framework for analysis of joint impact of atmospheric turbulence and refractivity on laser beam propagation, in: OSA Conference: Propagation through and Characterization of Distributed Volume Turbulence and Atmospheric Phenomena, PM4C-1, 7-11 June 2015, Arlington, Virginia, USA, 2015.

Vrancken, P., Wirth, M., Ehret, G., Barny, H., Rondeau, P., and Veerman, H.: Airborne forward-pointing UV Rayleigh lidar for remote clear air turbulence detection: system design and performance, Appl. Optics, 55, 9314-9328, 2016.

Weitkamp, C.: Lidar: Range-Resolved Optical Remote Sensing of the Atmosphere, Springer Science and Business, New-York, USA, 2006.

der Werf, S. Y.: Ray tracing and refraction in the modified US1976 atmosphere, Appl. Optics, 42, 354-366, 2003.

Whiteman, D. N., Melfi, S. H., and Ferrare, R. A.: Raman lidar system for the measurement of water vapor and aerosols in the Earth's atmosphere, Appl. Optics, 31, 3068-3082, 1992.

Zuev, V. E. and Zuev, V. V.: Remote Optical Sensing of the Atmosphere, Gidrometeoizdat, Moscow, 232 pp., 1992. 